\title{
A Perspective on a Management Information Systems (MIS) Program Review
}

\author{
Bee K. Yew \\ Fayetteville State University, Fayetteville, NC, USA \\ byew@uncfsu.edu \\ Executive Summary
}

This paper highlights relevant curriculum issues that were identified in a Management Information Systems (MIS) program review undertaken by a group of business faculty in a small regional university. The program review was initiated to improve job marketability of graduates and student enrollment. The review process is described as a collective effort in continuous improvement in program planning and assessment. A reference framework on the technical-business orientation of the program is applied. The framework explains the varying degree of emphasis in technical/business knowledge and skills in Information Technology (IT) and Information Systems (IS) programs. Outcomes associated with the program review process include new elective courses in MIS Internship/Co-Op and Supply Chain Management and increased emphasis in both technical and business skills in MIS courses.

The initial focus of this program review was to identify critical job skills for MIS majors through IT professional job descriptions and IT job market statistics. These sources of information led to several viewpoints that the program should emphasize more the "T" for technical skills. The "I" for business knowledge and skills in IT was overlooked or largely ignored. Further literature review on MIS (or IS) program reviews and IT outsourcing job trends indicated that business skills, such as communications and collaborative work skills, are important, and business knowledge in integrative value chain processes is valued by employers. Project management and system integration knowledge and skills are also valued as more enterprise applications are being implemented in business organizations.

With perfect information, curriculum design or redesign decisions could be highly rational and effective. Information about job placement rates for graduates, feedback from alumnus, inputs from employers and recruiters, and IT job trends are useful for aligning curriculum with the job market. For a new program, this information is either not available or limited. Adopting the systems approach for decision analysis, student characteristics are examined as input to the program. A significant number of our incoming undergraduate business students have little or no background in IT, nor do they have a notable background in problem-solving and analytical skills.

Material published as part of this publication, either on-line or in print, is copyrighted by the Informing Science Institute. Permission to make digital or paper copy of part or all of these works for personal or classroom use is granted without fee provided that the copies are not made or distributed for profit or commercial advantage AND that copies 1) bear this notice in full and 2) give the full citation on the first page. It is permissible to abstract these works so long as credit is given. To copy in all other cases or to republish or to post on a server or to redistribute to lists requires specific permission and payment of a fee. Contact 0HPublisher@InformingScience.org to request redistribution permission.
Therefore, a primary focus in developing technical programming skills is not expected to be an appropriate focus for this program.

"Attractiveness" of the program to students is an enrollment issue that is also discussed during this process. To increase student enrollment to the program, the group identified IT certification program offering, student internship and co-op program, new courses, and 
recruitment strategies as important steps to follow through.

Keywords: management information systems, information technology, information systems, curriculum, IT-IS orientation, job marketability, IT job trends, technical skills, business skills.

\section{Introduction}

Periodic program reviews are important for a continuous curriculum improvement initiative. Colleges or schools seeking accreditation or re-accreditation from various establishments go through a process of analyzing and reporting information that testify to the quality of their programs. This process usually requires a comprehensive evaluation of programs that is effort-intensive for faculty and administrators. In most cases, a successful accreditation is the result of effective, continuous improvement program activities that have been implemented and documented for the reporting period.

The program review for the case highlighted in this paper focuses on the first periodic review for the MIS program. The University of North Carolina system academic planning process policy requires progress reporting for new programs at its $1^{\text {st }}$ to $2^{\text {nd }}$ year and $3^{\text {rd }}$ to $4^{\text {th }}$ year of operation (University of North Carolina, 2003). Such reporting requirement provides rationale for decisions to allocate limited funds to support productive academic programs.

In this case, the program review directive from the Dean provides for a faculty initiative in program improvement. An expected process outcome is that a consistent view of a program direction among faculty members could lead to a more synergistic continuous improvement effort in curriculum development. Such potential benefit is subject to group dynamics within the structural and contextual dimensions of the academic unit.

The MIS program review in this small regional southeastern university was initiated based on several concerns. The MIS program in question is an undergraduate program that has evolved from a concentration program within the Business Administration degree program in the Management department. The program review occurred at its second year of operation and a few months after the School of Business had completed a successful review process for the AACSB accreditation of its programs. Faculty and administrator concerns for the MIS major program were: a lack of technical skill emphasis in course content, employment marketability of graduates, and enrollment of majors in the program. During the review process, the first two concerns became a single concern when a junior faculty member viewed programming skills as the key to job marketability for our graduates.

The program review effort was a new experience for six MIS faculty members and the chair of the department. The process evolved from an initial focus on MIS graduates getting jobs in the IT industry. Tasks assigned to faculty were to look for job positions in IT and to identify knowledge and skill competencies suitable for our graduates. This effort resulted in divergent thinking on jobs deemed suitable for our graduates.

The discussion on MIS program review in this paper will be organized in the following sequence: a review of existing literature on IS/IT job skills and IT industry trends, an overview of the program review process, IS-IT program orientation, alignment of program with job market, and conclusions about the process.

\section{Literature Review}

Literature identified to be relevant for the purpose of this program review can be broadly categorized as: 1) industry expectations of MIS graduates, and 2) IT job outlook and trends. 


\section{Industry Expectations}

Trauth, Farwell, and Lee (1993) focused on the perception gap between industry participants' and IS professors' perceptions of important IT knowledge/skills in the New England region. Their study concluded that, while knowledge/skills in three areas -1) technology and applications integration, 2) business processes, and 3) interpersonal skills - are perceived to be important by IS professionals, they were not emphasized in IS curricula. Trauth et al. suggested that the lack of rewards in curriculum development coupled with campus recruitment criteria that favored technical skills over soft skills might be the reasons for the expectation gap between the needs of the industry and the programs that prepare majors to meet employers' needs. Their study indicated that integration knowledge and skills are demanded, as new technologies are required to co-exist with prevailing environments in joint ventures, mergers, downsizing, globalization, and cost control initiatives. They suggested that internships and cooperative education programs could offer more realistic environments for students to learn about systems integration. In their conclusions, they also noted that the increasing trends in end-user developed applications, off-the-shelf software, telecommunications, systems integration, and outsourcing have generated multiple entry points for IS careers, ranging from technical to functional orientation. The continuum of IS career paths refers to a technical specialist as someone who is required to have a strong understanding in one or more specific technologies, such as telecommunications/networking, database, and operating systems, while the functional IS professionals must demonstrate a strong understanding of business areas and diverse technology solutions.

Todd, McKeen, and Gallupe's (1995) content analysis of IS positions looked at the count and proportion of technical and business knowledge/skills requirement phrases in job advertisements. Their results indicated a high number of phrases that referred to technical skills requirements in job advertisements, with an increasing trend for technical skills in programmer, analyst, and manager positions in the service industry. Although the number of phrases for business skill requirements is significantly fewer than for technical skills, there is an increasing trend for business skill positions. Their conclusions are that technical skills, knowledge of business, problem-solving skills, and general management skills are important, and emphasis on technical skills over "soft" or business and interpersonal skills should be further examined to address a perceived recruitment gap. The recruitment gap defined by the authors is a mismatch between the criticality of "soft" or business skills as perceived by senior IS managers and practices by lower level managers/supervisors who have strong preferences in hiring based on specific technical skills.

In another study, academicians and practitioners in IT ranked the importance of variables defined for IS core knowledge and skills and software tools (Lee, Koh, Yen, \& Tang, 2002). Their results indicate that perception gaps exist for IS core knowledge and skills. Practitioners' mean rankings for knowledge about organizations and training skills were found to be significantly higher (or more important) than academicians. Overall, the practitioner sample ranked interpersonal skills and personal traits to be more important than core IS knowledge in technologies and organization or business. In the area of software tools, academicians ranked most of the 29 software tools to be more important than the practitioners, with both groups concurring on electronic tools as the most important, and Internet/navigation, office productivity, and query tools to be very important.

There were several inconsistencies on perception of tool importance between the two groups, notably the project management tool. Practitioners ranked this tool to be very important $\left(5^{\text {th }}\right.$ ranking) while academicians ranked this tool to be not that important $\left(18^{\text {th }}\right.$ rank). Expert systems, procedural languages, decision support systems, simulation, and statistical tools were also considered to be less important by practitioners.

Noll and Wilkins (2002) conducted a survey to elicit the importance of IS skills in three staffing groups. The results of their analysis are summarized in Table 1. 
Table 1: Staffing Groups and Critical Skill Factors

\begin{tabular}{|l||l|l|l|}
\hline \multirow{2}{*}{\multicolumn{1}{|c||}{ Critical Skills Factors }} & \multicolumn{3}{c|}{ Factor mean values for Staffing Groups } \\
\cline { 2 - 4 } & Programmer & Analyst & User Support \\
\hline \hline Business Knowledge & 3.95 & $\underline{\mathbf{4 . 5 0}}$ & $\mathbf{3 . 8 2}$ \\
\hline Advanced IS Applications & 3.18 & $\underline{3.31}$ & $\mathbf{2 . 8 5}$ \\
\hline User Support & $\mathbf{3 . 3 5}$ & 3.64 & $\underline{4.44}$ \\
\hline Programming & $\underline{4.09}$ & 3.73 & $\mathbf{2 . 7 3}$ \\
\hline Systems Planning & 3.15 & $\underline{3.79}$ & $\mathbf{2 . 9 5}$ \\
\hline
\end{tabular}

Based on Noll and Wilkins (2002)

In Table 1, underlined numbers denote the highest mean values for each factor across the staffing groups. The bolded italicized numbers indicate the lowest mean values for each factor. For the programmer group, business knowledge and programming are almost equally important critical skill factors. For the analyst group, business knowledge is clearly the most important factor, while for the user support group business knowledge is the second most important factor. All skill factors are relatively important for the Analyst group. Noll and Wilkins (2002) recommendations for IS curricula for the staffing groups studied included:

- Knowledge of business functional areas, business environment and specific industry

- Ability to interpret business problems and to develop appropriate technical solution

- Ability to work collaboratively in a team project environment, and to plan, organize and lead projects

- Ability to develop and deliver effective, informative and persuasive oral presentations, and to write technical manuals, documents and reports

Ehie (2002) focused on industry expectations of MIS graduates as a basis for development of a new MIS program. Their development strategy involved an extensive review of literature and current programs and obtaining input from MIS professionals and employers on a draft program proposal. Their study concluded that, "employers are looking for individuals with a strong systems orientation and a good understanding of an integrative business value-chain" (Ehie, 2002, p. 151). On programming skills, interviews with employers revealed that in-house training opportunities are available, and while MIS hires are not expected to be programmers, "a general knowledge of programming logic and thought process with reasonable proficiency in at least one programming language" is desirable (Ehie, 2002, p. 156). People and communication skills were considered critical for developing working relationships with clients from diverse backgrounds and needs.

In investigating skills and knowledge required by IS professionals in their jobs, Wade and Parent (2002) analyzed the relationship between job skill deficiency/surplus and performance for the Webmaster position. Although a job content analysis on descriptions for 800 Webmaster positions indicated that they are primarily technical positions with requirements for limited organizational skills, their empirical study revealed that organizational or "soft" skill deficiencies have a larger negative effect on job performance than technical skill deficiency. The measurement of skill deficiency or surplus in the study was based on participants' perceptions of the usefulness and proficiency of organizational and technical skills. The set of organizational skills defined in the study included communications, project management, teamwork, customer service, and general management skills. Measurement of technical skills includes perceived proficiency and use- 
fulness of tools such as Windows, Unix, HTML, Perl, and Visual Basic. The authors concluded that a balance of technical and organizational skills is important for perceived job performance.

Surveys of graduates in an IS program indicated that non-technical skills are considered to be more important than technical skills (Davis \& Woodward, 2006). In this study, the results of surveys for graduates from 1999 to 2005 were combined and analyzed. Participants in this survey ranked the importance of thinking skills, personal characteristics, teamwork skills, and communication skills for their jobs. A breakdown of graduates hired in different areas is technical/user support (35\%), computer programming (12\%), networking (11\%), and database design ( $9 \%)$, with providing technical support (54\%) and installing software (45\%) as the top two tasks performed on a regular basis. Table 2 shows the percentages of graduates' employment areas based on 179 graduates:

Table 2: Primary Job Focus of Graduates Employed in IT Areas

\begin{tabular}{|l|l|}
\hline Job Focus in Different Areas & \multicolumn{1}{|c|}{ Total } \\
\hline Technical/end user support & $34.6 \%$ \\
\hline Computer programming & $12.3 \%$ \\
\hline Networking & $10.6 \%$ \\
\hline Database design/development & $8.9 \%$ \\
\hline Web design/development & $6.7 \%$ \\
\hline Information management & $6.2 \%$ \\
\hline System analysis/design & $3.9 \%$ \\
\hline Information security & $2.2 \%$ \\
\hline Information management and security & $1.7 \%$ \\
\hline E-commerce & $0.6 \%$ \\
\hline Other & $12.3 \%$ \\
\hline
\end{tabular}

Based on Davis, Woodward, and Belle (2006)

* refers to combining the results of surveys for graduates from 1999 to 2005

\section{IT Job Outlook and Trends}

Most students consider job prospects a significant factor in their decisions to major in a field of study. Therefore, the student perception of job prospect associated with the degree is expected to be a major factor in determining the "attractiveness" of a program. The job outlook for IT/IS industry was researched to aid alignment of MIS program focus with job market outlook.

For the faculty involved in this MIS program review, defining which IT positions to focus on for development of critical skills and knowledge competencies was less straightforward than initially assumed. This was due to 1) lack of clarity about IT positions, and 2) diverse IT/IS positions ranging from technical to functional (or business) orientation.

The US Bureau of Labor Statistics (BLS) publishes a biennially updated Occupational Outlook Handbook that provides important career information about the job market (U.S. Department of Labor, Bureau of Labor Statistics, 2008-9). The BLS classification of occupations has ten major groups in which there are subgroups. Descriptions for IT-related professions are found in the subgroup titled "Computer and Mathematical Occupations" which is then grouped under "Professional and related occupations". The "Computer and Mathematical Occupations" subgroup classification of IT jobs could be misleading to students who are not drawn towards fields that require 
strong mathematics or computer science education. In fact, a number of IT positions do not require advanced mathematics beyond that which is normally found in business programs.

The BLS job projection summary data extracted from the November 2007 Monthly Labor Report shows projected increases (2006 to 2016) for the top three IT professional categories (Dohm \& Schniper, 2007). These three categories are computer and information systems managers, computer specialists and computer hardware engineers. The data are shown in Table 3.

Table 3: Projected Employment for Professional IT workers in United States by Occupations for the Period 2006-2016 (in thousands)

\begin{tabular}{|l|c|c|c|}
\hline SOC Major group ${ }^{1}$ : Computer and Mathematical Occupations & 2006 & 2016 & \% of change \\
\hline \hline Computer and information systems managers & 264 & 307 & $+16.36 \%$ \\
\hline Computer specialists: & 25 & 31 & $+21.53 \%$ \\
Computer and information scientists, research & 435 & 417 & $-4.14 \%$ \\
Computer programmers $^{\text {Computer software engineers, applications* }}$ & 507 & 733 & $+44.55 \%$ \\
Computer software engineers, systems software* $^{*}$ & 350 & 449 & $+28.18 \%$ \\
Computer support specialists $^{2}$ & 552 & 624 & $+12.88 \%$ \\
Computer systems analysts* $^{*}$ & 504 & 650 & $+28.98 \%$ \\
Database administrators* & 119 & 154 & $+28.56 \%$ \\
Network and computer systems administrators & 309 & 393 & $+26.95 \%$ \\
Network systems and data communications analysts* & 262 & 402 & $+53.41 \%$ \\
All other computer specialists & 136 & 157 & $+15.12 \%$ \\
\hline Computer hardware engineers & 79 & 82 & $+4.6 \%$ \\
\hline Total, all professional-level IT occupations & 3,543 & 4,395 & $+24.05 \%$ \\
\hline Total, all occupations & 150,620 & 166,220 & $+10.36 \%$ \\
\hline
\end{tabular}

Based on Dohm and Schniper (2007)

1: The U.S. Standard Occupational Classification (SOC) is a universal occupational classification system that is developed by various federal agencies to allow for comparison of occupational statistical data and to monitor evolution of occupations

2: "Computer Support Specialists" includes technical support specialists and help desk specialists

*: These occupations are among the 30 occupations that have been projected to be the fastest growing with rates of at least $27 \%$ for the period 2006 to 2016

In Table 3, the "all other computer specialists" category is a residual catchall label that includes various job titles not found in the BLS occupational classification system (Subramaniam \& Burnett, 2007). IT-related job titles such as "software trainer," "knowledge management specialist," "BI specialist," "technical writer," "computer IT analyst," "e-business specialist," and "user interface analyst" are expected to be included in this category. In researching job positions appropriate for the program review, the use of several job titles for similar job descriptions could be potentially misleading for student and faculty. For example, the job description for a "Business Analyst" is similar to that of the "Systems Analyst" and the "Requirements Analyst" positions. The International Institute of Business Analysis (2008) described a business analyst to be someone who has strong business functional and technical knowledge/skills and who performs duties such as user requirements analysis and recommend improvements in business processes based on IT. Comparisons between systems analyst and business analyst job titles are inconclusive as they are used interchangeably in organizations for the same role. There are some differences between 
these two roles in that a systems analyst is more technically proficient in coding, and a business analyst is more functionally proficient in business and management (deBree, 2007).

In Table 3, job titles indicated with an asterisk next to them are among the list of 30 fastest growing occupations published in the Monthly Labor Review (Dohm \& Schniper, 2007). These jobs are also ranked to be "Very High" in annual median salary (at least $\$ 46,360$ ), for which a college degree is the most significant source of postsecondary education and training.

The 2004 annual workforce development survey report (Information Technology Association of America, 2004) reported the best backgrounds for all IT employment job categories defined by the National Workforce Center for Emerging Technologies. Their results were based on a survey of 500 practitioners who oversee the hiring of IT staff (Table 4).

Table 4: Hiring Managers' Indications of Best Background for IT Job Categories

\begin{tabular}{|c|c|c|c|c|c|c|c|c|}
\hline IT Job Categories & 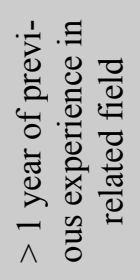 & 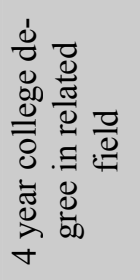 & 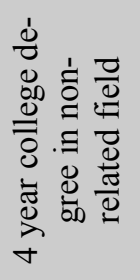 & 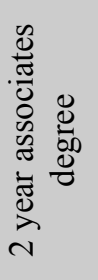 & 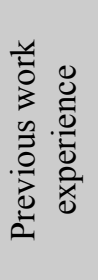 & 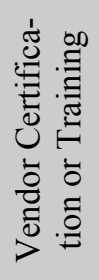 & 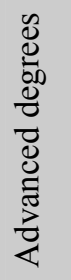 & 苛 \\
\hline Tech Support & $58 \%$ & $42 \%$ & $2 \%$ & $27 \%$ & $24 \%$ & $20 \%$ & $2 \%$ & $7 \%$ \\
\hline $\begin{array}{c}\text { Database } \\
\text { development or } \\
\text { administration }\end{array}$ & $48 \%$ & $50 \%$ & $3 \%$ & $15 \%$ & $17 \%$ & $15 \%$ & $3 \%$ & $18 \%$ \\
\hline $\begin{array}{l}\text { Programming or } \\
\text { software } \\
\text { engineering }\end{array}$ & $47 \%$ & $51 \%$ & $1 \%$ & $12 \%$ & $15 \%$ & $11 \%$ & $5 \%$ & $23 \%$ \\
\hline $\begin{array}{l}\text { Web development } \\
\text { or administration }\end{array}$ & $53 \%$ & $39 \%$ & $3 \%$ & $19 \%$ & $18 \%$ & $15 \%$ & $3 \%$ & $19 \%$ \\
\hline $\begin{array}{c}\text { Network systems } \\
\text { design or } \\
\text { administration }\end{array}$ & $53 \%$ & $51 \%$ & $4 \%$ & $15 \%$ & $18 \%$ & $22 \%$ & $3 \%$ & $11 \%$ \\
\hline $\begin{array}{c}\text { Enterprise systems } \\
\text { analysis or } \\
\text { integration }\end{array}$ & $40 \%$ & $43 \%$ & $3 \%$ & $8 \%$ & $14 \%$ & $14 \%$ & $4 \%$ & $32 \%$ \\
\hline Digital media & $35 \%$ & $21 \%$ & $2 \%$ & $18 \%$ & $14 \%$ & $10 \%$ & $3 \%$ & $44 \%$ \\
\hline Average & $46 \%$ & $41 \%$ & $3 \%$ & $16 \%$ & $17 \%$ & $14 \%$ & $3 \%$ & $25 \%$ \\
\hline
\end{tabular}

Based on Information Technology Association of America Annual Workforce Development Survey (2004).

The percentages in Table 4 show the proportion of managers who selected a background as 'best' for hiring decisions in each job category. Since the row percentages do not add up to $100 \%$, it is speculated that managers in the survey were allowed to indicate more than one background for hiring decisions. This refers to managers who would consider hiring junior and senior positions within the same job category. . The summary statistics show that, "experience is still important but for many IT jobs getting the right degree could mean getting the right opportunity" (Information Technology Association of America Annual Workforce Development Survey, 2004, p. 10). Hiring managers consider the "combination of previous experience in a related field (an average of $46 \%$ ) and a 4-year college degree in a related field (an average of $41 \%$ ) as the most important preparation for job attainment" (p. 10). 
Of particular interest to the program review group is the vendor certification or training background. The summary statistics shows that for Tech Support, and Network Design and Administration more than $20 \%$ of managers consider vendor certification/training as the best background in hiring decisions. This led to our review group considering the possibility of partnerships with community colleges to offer certification programs in these areas to increase job placement rates for program graduates. It was also noted that a background of less than 1 year of experience has significant weight in hiring decisions. Our review group felt that internship and cooperative education programs might serve as good substitutes for the experience.

In addition to evaluating market demand for critical skills in the IT industry, a broader look at general trends is important for shaping IS curriculum. The increasing use of offshoring IT tasks is a matter for concern to IT graduates. Jobs that require specialized IT skills, such as global project management, large-scale integration, system architecture, and IT liaison, are predicted to more commonly stay onshore (Shao \& David, 2007). Localized activities that require face-to-face interactions with clients are also more likely to say onshore, for example, security expertise, preliminary requirement analysis, and logic design, system testing/deployment, and user training. Other jobs that are less vulnerable to losses involved activities that support core, evolving business functions that are tied to the firm's bottom-line, such as supply chain management, logistics, and inventory management. On the other hand, non-core business processes, such as human resources, accounting, and financial reporting, are at risk of being outsourced to offshore providers. Routine labor-intensive IT tasks that require little or no interactions with clients, such as "nutsand-bolts" programming in application development, detailed design, program coding and testing, and systems maintenance and support, are also expected to move offshore. These projections imply the need for a shift in focus for MIS programs to reduce emphasis in technical programming skills and knowledge in non-core business processes and to increase emphasis in project management, system integration, computer networking and communications skills, and knowledge about core business processes and technologies.

\section{The Review Process}

Fayetteville State University is a member of the University of North Carolina system of 16 public institutions and is a historically black institution established to serve the minority community of African Americans. The university is ranked by the 2008 America's Best Colleges publication to be in the Tier 1 group of historically black colleges and universities (Morse \& Flanigan, 2007).

The MIS program review was initiated out of concerns for program focus and enrollment. The outcome for the review process was a report on strategies to strengthen the program. In Spring 2008, the MIS program at Fayetteville State University had 46 MIS student majors, 12 Management student majors with MIS concentration, and 45 MIS student minors. MIS student minors were mostly Accounting and Computer Science student majors.

The faculty group consists of seven members. Six faculty members teach at least two MIS courses every semester, and five also teach Management courses in Operations Management, Quantitative Methods, or Business Statistics. The process for the review is illustrated in the Figure 1: 


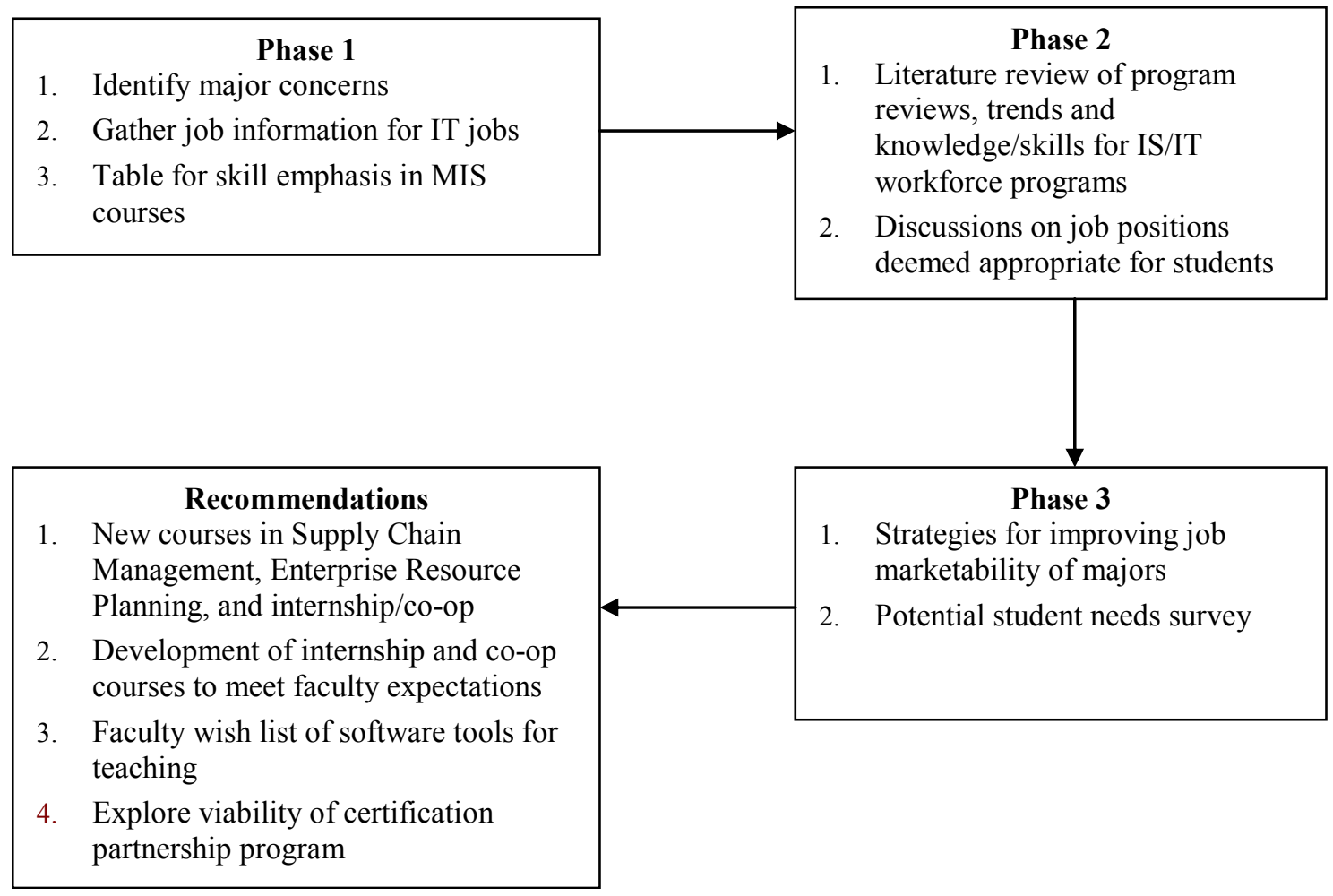

\section{Figure 1. MIS Program Review Process Flowchart}

In Phase 1, enrollment and technical skills emphases in the program were discussed. An informal survey of positions advertised on the Internet identified skills in demand. A table with skills in demand was circulated among MIS faculty to gather details on technical-related skills covered in each course with an additional column for the faculty to suggest any additional skills and software tools required for the course (see Appendix). Further discussion about the courses listed in the table is provided in the section on alignment of MIS curriculum with the job market.

Junior faculty with doctoral degrees in the area of Operations Management identified a set of technical skills that were in demand for technical positions, such as database developers or engineers, system analyst, web developers or engineers, and web designers. However, a few faculty members thought that it would be more appropriate to analyze skills for positions that are functionally (or business) oriented, such as business analyst, information specialist, junior database analyst, and assistant project manager positions. All MIS faculty have programming proficiency in at least one programming language: $\mathrm{C}$, Java, VBA, macro, and procedural languages. The program requires all MIS majors to take a 200-level VBA programming course and offers an elective course in Java programming. This minimal level of programming does not prepare our students to assume technical positions that require programming skills.

While the majority of faculty in the group agreed that a greater emphasis on programming skills would help to build students' problem solving and logic thinking skills, there were practical concerns - such skills are often considered difficult by the average college student. Limited faculty experiences in teaching programming courses with insufficient computer lab resources are other practical concerns. Furthermore, it is expected that in developing and making revisions to our curriculum, we should consider the consequences of creating in-house competition with the computer science program for students and resources. With an enrollment of less than 50 student majors for the program, a decision on program focus would depend on the use of current faculty and facility resources. More importantly, research in industry expectations and job outlook and trends 
indicate that project management, systems integration, computer networking, and communications skills are more critical than programming skills.

In the second phase, the concerns for the direction of the program review led to referencing the computing-related programs or disciplines established by the Association of Computing Machinery (http://computingcareers.acm.org/). Further discussion of the IT-IS orientation of two of these programs is found in the IT-IS program orientation section of this paper.

In the third phase, enrollment concerns were discussed including the need to increase recruitment efforts in a nearby military base. Two faculty members, who were teaching courses in the military base, designed a survey to collect information about interest level in the program. The survey revealed that more than $60 \%$ of the respondents would be interested in a program that focused on logistics and supply chain management topics. Other potential recruitment activities included linking student organization activities with recruitment effort and faculty participation in events sponsored by the university, such as the open house event and high school visits, and the School of Business sponsored event for new incoming freshmen. In the final phase, a brief report was prepared with recommendations that included new courses, recruitment strategies, and IT certification programs. A presentation of the report and a group discussion session with the Dean of the School of Business concluded the process.

\section{IT-IS Program Orientation}

The faculty group tackled the issue of job marketability of graduates by first identifying appropriate IS positions for graduates of the program. Initial attempts resulted in technical positions that led to the research literature review process. The process identified the need to clarify the program orientation. For our program, the IS-functional orientation was found to be more appropriate for current student and faculty backgrounds. The next step in the process identified the appropriate mix of technical and business knowledge/skills required to graduate students with marketable skills in positions targeted to be suitable for the program.

An outcome of the initial focus on job positions revealed an issue with business (or functional) and technical orientations of the program. Guidelines for establishing the program came from two sources: selected IS/MIS programs in other business schools and faculty input. The approach of benchmarking may not have offered the best approach if these selected programs were misaligned with current IT job market trends for skills and knowledge competencies. Additionally, we needed to acknowledge that student backgrounds, program visibility, recruiting efforts, and regional job opportunities might affect graduates to a significant degree in terms of employment marketability. For example, large consulting firms hire non-MIS or non-CS graduates such as Math or English majors for their IT positions. Personal traits (soft skills) such as analytical, problem-solving, and communication skills are seen to be critical assets in these IT career positions. These new hires go through on-the-job training assignments and career building programs to acquire highly demanded technical IT knowledge or skills sponsored by the company.

Misunderstandings and different perspectives on the issue of orientation prompted a need for a reference point for the discipline. The ACM Internet career guide for IS programs states "IS professionals must understand both technical and organizational factors, and must be able to help an organization determine how information and technology-enabled business processes can provide a foundation for superior organizational performance. They serve as a bridge between the technical and management communities within an organization," and the fact that, "majority of IS programs are housed in business schools, and may have different names such as Management Information Systems (MIS), computer information systems (CIS), or business information systems (BIS)" (Association for Computing Machinery, n.d.). 
In general, MIS and IS-related degree programs have varying degrees of emphasis in business and technical topics in program learning goals. Programs differ substantially in the development of knowledge/skill in programming, data administration, and networking topics. In determining the orientation of the program under review in this case, two of the ACM's computing disciplines, Information Technology (IT) and Information Systems (IS), are used to construct a continuum model for identifying program orientation in development of technical and organization (functional) knowledge/skills. According to the ACM, graduates of IT programs are expected to be knowledgeable on a selection of appropriate hardware/software and be able to integrate technology infrastructure to meet the needs of the organization, while providing a secure and effective environment to support its users' computing activities. IT graduates are, therefore, expected to be knowledgeable about scripting languages to connect existing system components. The IS graduates, on the other hand, must demonstrate a strong understanding of both technical and organization factors and be able to help the organization to determine how information and business processes can support its business goals. Thus, the concern for lack of technical skills in the program should, therefore, be reflected in the context of technical and functional orientation. The multiple entry career points in IS career path as suggested by Trauth, Farwell and Lee's (1993) study implicates curriculum design to the diverse roles of IS professionals

\section{Alignment of MIS Curriculum with Job Market}

A summary of current emphasis of MIS skills and new skills identified for existing courses for the program is provided in a table in the Appendix. The second column provides a general description of the courses. Courses such as MIS 330 Systems Analysis and Design and MIS 331 Systems Development have coverage of business processes for learning system modeling tools, user requirement, and system design techniques. A review of the course content in the MIS curriculum led to the identification of additional skills that should be added to each course to improve the skill set for business analyst, junior system analyst, and project management assistant positions. To strengthen the MIS curriculum, additional resources and software are required. The two greatest needs are better access to CASE tools and a network lab for students to have "handson" learning experience in network security and configurations in the MIS 430 Data Communications and Network course.

The MIS Internship/Co-op program is expected to provide students with learning experiences that will help them to understand the complexities of IT technologies employed to serve the business needs of organizations and its users. These experiences may include learning specific software packages, setting up computer networks, installing software, and understanding teamwork and building communications skills. Development of the internship/co-op program requires faculty to define formative assessment of students and resources needed to establish the program. MIS 498 (Internship) and MIS 499 (Co-op) are two new courses added to the MIS program.

Based on the group's review on IT certification, faculty development in certification and partnership with community colleges in offering certification program emerged as strategies to improve program visibility and graduates job marketability.

\section{Conclusions}

The program review process described in this paper was an initiative designed to increase program enrollment and relevancy in preparing graduates for the job market. Implemented outcomes associated with the process were new courses such as MIS internship and co-op (cooperative), faculty involvement in MIS education conferences, availability of funds for establishing certification programs, and continuing effort in rethinking curriculum. Continuous effort in curriculum evaluation requires assessment of learning outcomes. In assessment of student learning outcomes, faculty need to examine their course materials to reflect learning goals that are consistent with 
critical IS knowledge and skills identified in this review process. Although the diverse perspectives on the process goals and related curriculum issues bound the results of this review process, the author believes that the process is necessary to achieve a coordinated effort in program improvement. Various levels of faculty involvement in the process may be explained by perceived lack of reward or recognition in the process. Trauth et al. (1993) made a similar observation in their explanation for curriculum gaps that were found to exist in their study. A "piecemeal" approach and continuity in program review effort would likely to have better results than a single comprehensive review process due to limited faculty resources.

The learning outcome of this process is the view that our MIS graduates are to be employed for their business and information systems knowledge with team, communications, and analytical skills in applying software tools for improving business processes. In line with the concept of multiple career paths in IS, MIS students should be advised to increase their employability through their selection of course electives in the program.

Although the current MIS curriculum is designed to develop student competency in both business and IT areas, it is essential that students learn to synthesize the two knowledge areas and apply them to business situations. Topics in Enterprise Resource Planning (ERP), Customer Relationship Management (CRM), and Supply Chain Management (SCM) are to be included in coursework to improve student understanding of integrative business value chain. Software tools for these topics will need to be identified in a continuous curriculum development process to bridge theory with practice in these areas.

The 2004 Annual Workforce Development survey report in Table 3 revealed that certification is an important consideration for hiring decision in Network Design and Administration and Tech Support categories of IT jobs. Faculty resource constraints in setting up a full-fledged certification program will require collaborating with community colleges in offering IT certification to students to increase program enrollment.

Lee et al.'s (2002) perception gap study indicated that knowledge about IS technologies, such as packaged software products and trends, is considered to be important by practitioners. Additionally, project management, spreadsheet, and database software tools were considered by IS practitioners to be within the top ten important skills, along with electronic mail and query languages. Thus, an emphasis on technical skills in using application development software such as CASE and ORACLE, and MS Project 2003, are learning outcomes that will be included System Analysis and Development, Database, and Project Management courses. In courses such as Decision Support Systems and Introductory to Database Management Systems, more advanced Microsoft Excel, and Access skills that require students to learn about macros and some VB programming should be considered. The trend in enterprise application development means that our graduates must demonstrate a conceptual understanding of business applications and tools. "Soft" skills and their importance to employers require faculty to reinforce emphasis in such skills in core MIS subjects such as System Analysis and Design, Database Management Systems, and System Development.

Overall, the program review process was a good learning experience for the faculty as it resulted in broadening faculty perspectives on program focus based on the IT-IS continuum. Literature review related to current IT job trends increase faculty awareness of "value-added" business process knowledge in supply chain management and customer relationship management, and that "soft" skills such as communications, team and project management skills are competencies that are of value to employers. 


\section{References}

Association for Computing Machinery. (n.d.). Computing degrees \& careers: Information systems. Retrieved from http://computingcareers.acm.org/?page id $=9$

Davis, D. C., \& Woodward, B. (2006). An analysis of skills required of graduates of an information systems program. Information Technology, Learning, and Performance Journal, 24(2), 11-20.

deBree, T. (2007). Differences between systems analyst and business analyst. Retrieved June 28, 2008 from http://www.modernanalyst.com/Resources/Articles/tabid/115/articleType/ArticleView/articleId/185/D efault.aspx

Dohm, A., \& Schniper, L. (2007) Employment outlook: 2006-16: Occupational employment projections to 2016. Monthly Labor Review Online, 130(11), 93-98. Retrieved June 8, 2008, from: http://www.bls.gov/opub/mlr/2007/11/contents.htm

Ehie. I. C. (2002). Developing a management information systems (MIS) curriculum: perspectives from MIS practitioners. Journal of Education for Business, 77(3), 151-158.

Information Technology Association of America Annual Workforce Development Survey (2004). Adding value...growing careers: The employment outlook in today's increasingly competitive IT job market. Retrieved April 1, 2007 from http://www.pr.mala.ca/techcomm/documents/04workforcestudy.pdf

International Institute of Business Analysis, (2008) “Becoming a BA”. Retrieved June 23, 2008, from http://www.theiiba.org/AM/Template.cfm?Section=Becoming_a BA\&Template=/CM/HTMLDisplay. cfm\&ContentID $=2245$

Lee, S., Koh, S., Yen, D., \& Tang, H. (2002). Perception gaps between IS academics and IS practitioners: An exploratory study. Information and Management, 40, 51-61.

Morse, R., \& Flanigan, S. (2007). How we calculate the historically black colleges and universities rankings. Retrieved July 1, 2008, from http://www.usnews.com/articles/education/historically-blackcolleges/2007/09/28/historically-black-college-ranking-methodology.html

Noll, C. L., \& Wilkins, M. (2002). Critical skills of IS professionals: A model for curriculum development. Journal of Information Technology Education, 1(3), 143-154. Retrieved from http://jite.org/documents/Vol1/v1n3p143-154.pdf

Shao, B., \& David, J. S. (2007). The impact of offshore outsourcing on IT Workers in developed countries. Communications of ACM, 50(2), 89-94.

Subramaniam, M., \& Burnett, K. (2006). What's the matter with the information technology workforce? First Monday, 11(5). Retrieved June 27, 2008, from http://www.firstmonday.org/issues/index.html

Trauth, E. M., Farwell, D. W., \& Lee, D. (1993). The IS expectation gap: Industry expectations versus academic preparation. MIS Quarterly, 17(3), 293-301.

Todd, P. A., McKeen, J. D., \& Gallupe, R. B. (1995). The evolution of IS job skills: A content analysis of IS job advertisements from 1970 to 1990. MIS Quarterly, 19(1), 1-27.

U.S. Department of Labor, Bureau of Labor Statistics (2008-9). Occupational outlook handbook, 2008-9 edition. Retrieved June 15, 2008, from http://www.bls.gov/oco/oco1002.htm

University of North Carolina. (2003). Academic program development procedures. Retrieved October 19, 2007, from http://intranet.northcarolina.edu/docs/legal/policymanual/400.1.1.pdf

Wade, M. R., \& Parent, M. (2002). Relationships between job skills and performance: A study of webmasters. Journal of Management Information Systems, 18(3), 71-96. 


\section{Biography}

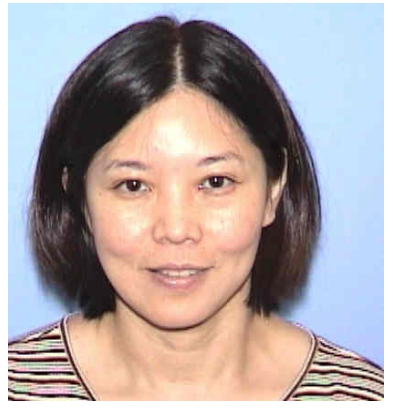

Dr. Yew earned her doctorate degree from Southern Illinois University at Carbondale. She has published in Information Technology, Learning and Performance Journal, Journal of the Operational Research Society, and Journal of Higher Education Management. Dr. Yew's publications have also appeared in DSI, INFORMS and IEEE Society proceedings. Her research interests include data mining, knowledge management and sharing, and self-directed learning. She also has a book chapter on knowledge management in Decision Support Systems: Achievements and Challenges for next Decade. 


\begin{tabular}{|c|c|c|c|c|c|c|c|}
\hline 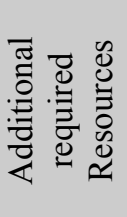 & & & & $\begin{array}{l}\frac{n}{0} \\
0 \\
e \\
1 \\
\\
0 \\
0\end{array}$ & $\begin{array}{l}\frac{n}{8} \\
0 \\
0 \\
\text { y } \\
0 \\
0 \\
0\end{array}$ & 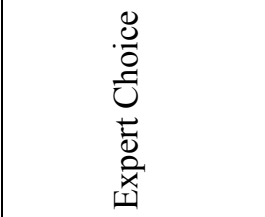 & 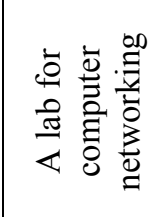 \\
\hline 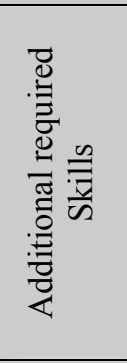 & 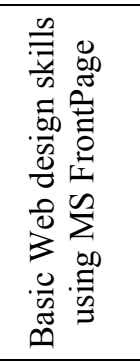 & 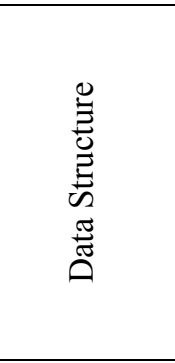 & 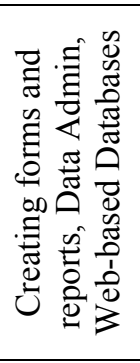 & 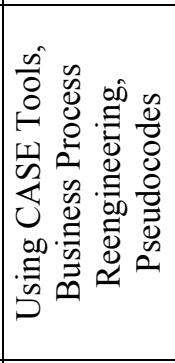 & 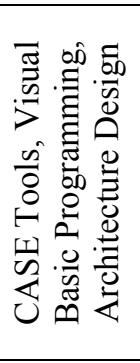 & 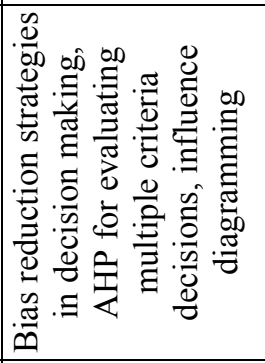 & 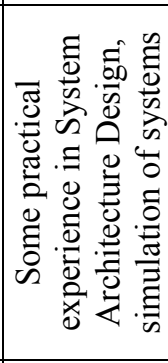 \\
\hline $\begin{array}{l}\frac{n}{0} \\
0 \\
0 \\
0 \\
\sum_{0}^{0} \\
0\end{array}$ & 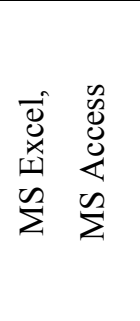 & 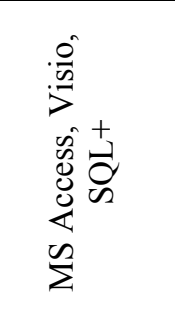 & $\stackrel{+}{\vec{\sigma}}$ & 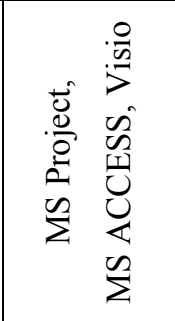 & 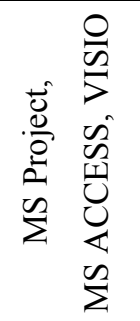 & 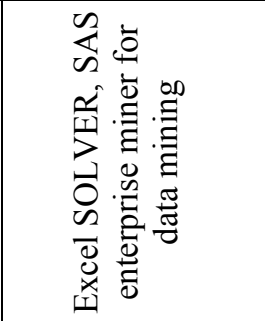 & $\frac{0}{\Omega}$ \\
\hline 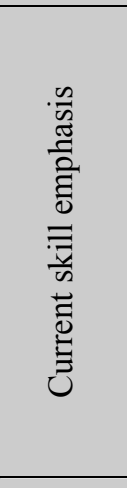 & 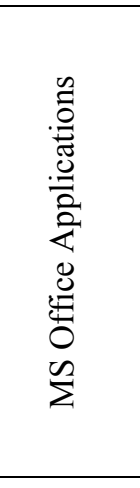 & 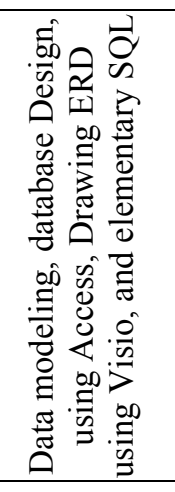 & 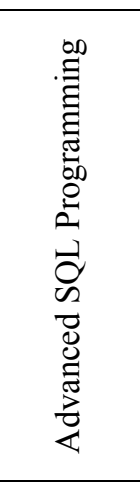 & 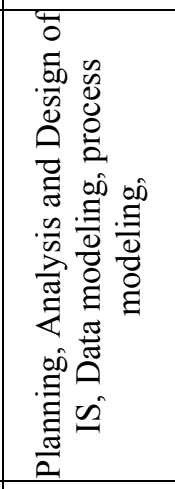 & 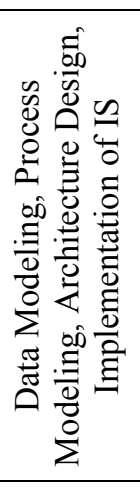 & 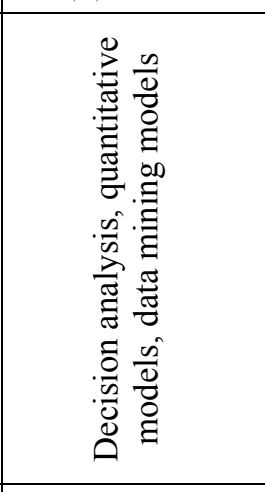 & 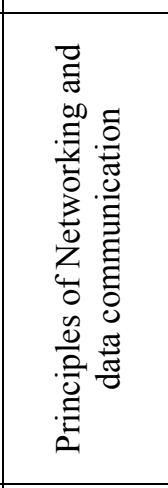 \\
\hline 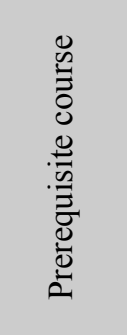 & 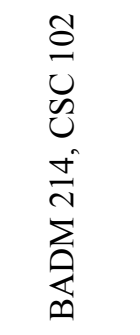 & 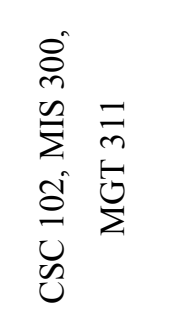 & $\begin{array}{l}\stackrel{ }{1} \\
\text { ñ } \\
\stackrel{\Sigma}{\Sigma}\end{array}$ & 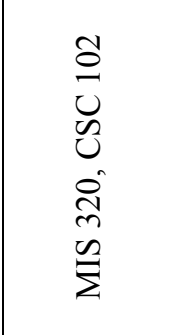 & $\begin{array}{l}0 \\
m \\
m \\
\infty\end{array}$ & 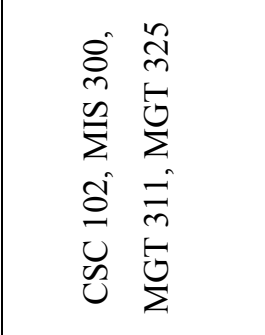 & $\begin{array}{l}8 \\
\infty \\
\infty \\
\sum\end{array}$ \\
\hline 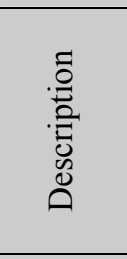 & 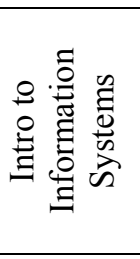 & 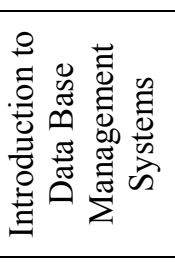 & 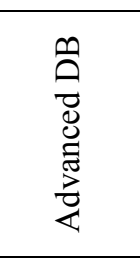 & 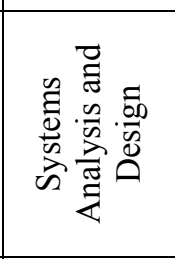 & 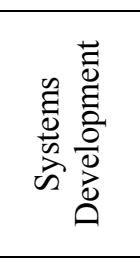 & 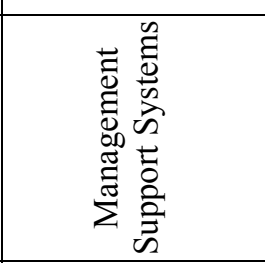 & 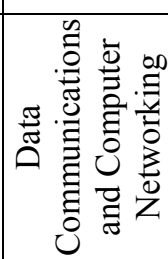 \\
\hline 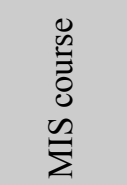 & $\begin{array}{l}8 \\
\infty \\
\tilde{N} \\
\sum\end{array}$ & $\begin{array}{l}* \\
\stackrel{2}{N} \\
m \\
\tilde{N} \\
\Sigma\end{array}$ & $\begin{array}{l}\frac{*}{\pi} \\
\tilde{n} \\
\tilde{n}\end{array}$ & $\begin{array}{l}* \\
\hat{0} \\
\tilde{n} \\
\tilde{n} \\
\dot{z}\end{array}$ & $\begin{array}{l}\frac{*}{m} \\
m \\
\infty\end{array}$ & 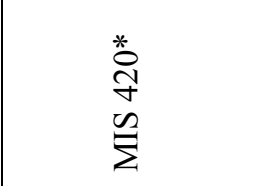 & 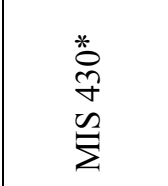 \\
\hline
\end{tabular}




\begin{tabular}{|c|c|c|c|c|}
\hline 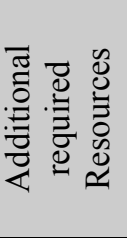 & & 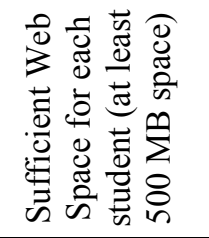 & & \\
\hline 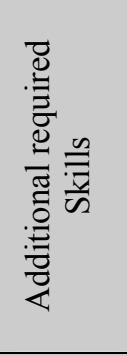 & & 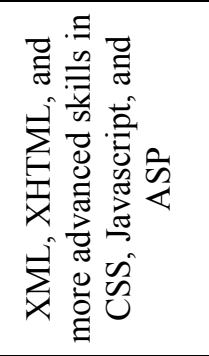 & 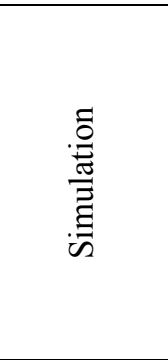 & \\
\hline $\begin{array}{l}\frac{n}{0} \\
8 \\
0 \\
0 \\
\sum_{0}^{0} \\
\infty\end{array}$ & 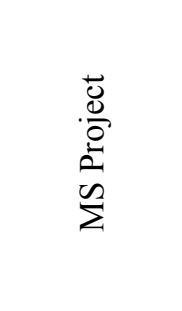 & 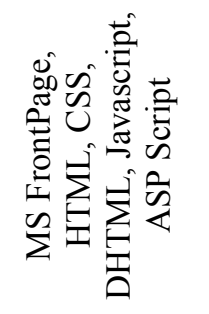 & 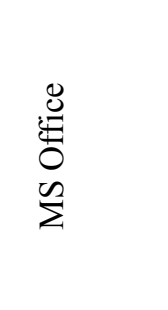 & $\underset{\nwarrow}{\mathbb{2}}$ \\
\hline 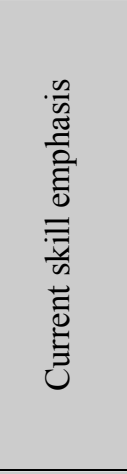 & 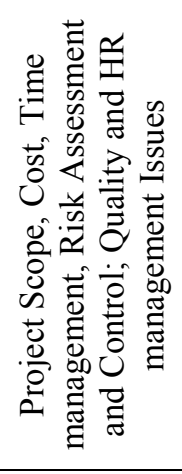 & 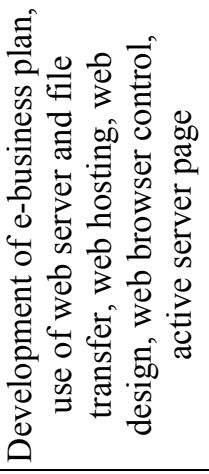 & 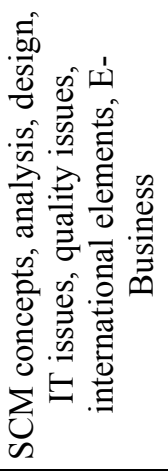 & 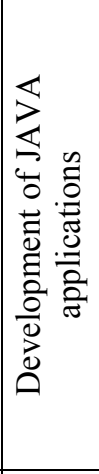 \\
\hline 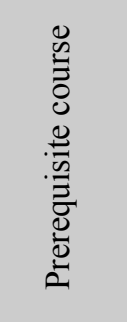 & 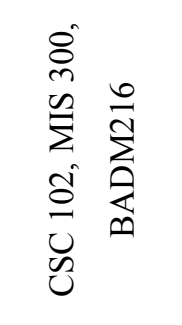 & 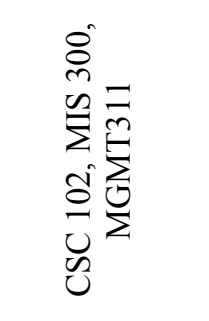 & 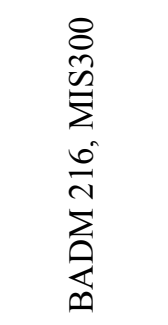 & $\begin{array}{l}8 \\
\infty \\
n \\
\sum_{1} \\
i 1 \\
0 \\
0 \\
0 \\
0\end{array}$ \\
\hline 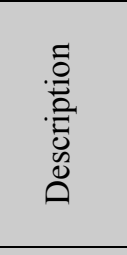 & 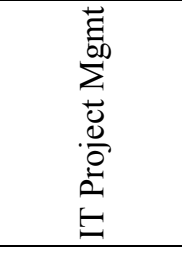 & 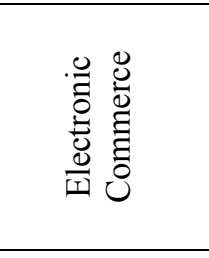 & 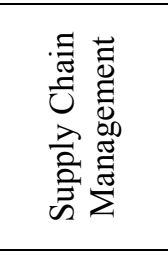 & 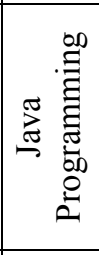 \\
\hline 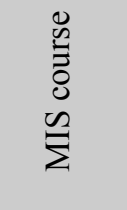 & 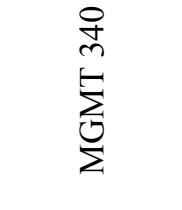 & 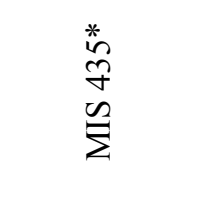 & $\begin{array}{l}\stackrel{0}{y} \\
\forall \\
\mathscr{J} \\
\sum\end{array}$ & 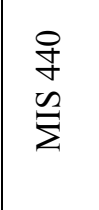 \\
\hline
\end{tabular}

